\title{
Video-assisted thoracoscopic surgery (VATS) lobectomy: Catastrophic intraoperative complications
}

\author{
Raja M. Flores, MD, ${ }^{\mathrm{a}}$ Ugonna Ihekweazu, MD, ${ }^{\mathrm{b}}$ Joseph Dycoco, BA, ${ }^{\mathrm{b}}$ Nabil P. Rizk, MD, ${ }^{\mathrm{b}}$ \\ Valerie W. Rusch, MD, ${ }^{\mathrm{b}}$ Manjit S. Bains, MD, ${ }^{\mathrm{b}}$ Robert J. Downey, MD, ${ }^{\mathrm{b}}$ David Finley, MD, \\ Prasad Adusumilli, MD, ${ }^{\mathrm{b}}$ Inderpal Sarkaria, MD, ${ }^{\mathrm{b}}$ James Huang, MD, ${ }^{\mathrm{b}}$ and Bernard Park, MD
}

\begin{abstract}
Objective: Large case series have demonstrated that video-assisted thoracoscopic surgery (VATS) lobectomy is feasible and safe. However, catastrophic intraoperative complications during VATS lobectomy requiring thoracotomy can be overlooked and are not reported in the current literature. We reviewed our experience to determine the frequency, management, and outcome of these complications.
\end{abstract}

\begin{abstract}
Methods: A systematic review of a prospective database was performed after institutional review board approval. All patients who underwent VATS lobectomy or a combination of any VATS procedure plus a thoracotomy were identified. A catastrophic complication was defined as an event that resulted in an additional unplanned major surgical procedure other than the planned lobectomy.
\end{abstract}

\begin{abstract}
Results: From 2002 to 2010, a total of 633 VATS lobectomies were performed and 610 patients had any VATS procedure plus a thoracotomy. Thirteen catastrophic complications were identified in $12(1 \%)$ patients. We included all cases in which a VATS was performed as well as a thoractomy since this would include conversions as well. These cases included 3 main pulmonary arterial and 1 main pulmonary venous transection requiring reanastomosis, 3 unplanned pneumonectomies, 1 unplanned bilobectomy, 1 tracheoesophageal fistula, 1 membranous airway injury to the bronchus intermedius, 1 complete staple line disruption of the inferior pulmonary vein injury to the azygos/superior vena cava junction, and 1 splenectomy. There were no intraoperative deaths.
\end{abstract}

Conclusions: Catastrophic intraoperative complications of VATS lobectomy are uncommon. However, awareness of the possibility of such injuries is critical to avoid them, and development of specific management strategies is necessary to limit morbidity should they occur. (J Thorac Cardiovasc Surg 2011;142:1412-7)

The use of video-assisted thoracoscopic surgery (VATS) lobectomy as a preferred surgical procedure for the treatment of lung cancer is increasing. An analysis of The Society of Thoracic Surgery (STS) database demonstrated that $20 \%$ of all lobectomies were performed by a VATS method. This study also revealed that the use of VATS lobectomy for the treatment of lung cancer has increased over the past 3 years from $21.6 \%$ in 2004 to $28.6 \%$ in 2005 to $32 \%$ in 2006. ${ }^{1}$ This increase is likely due to the growing clinical evidence that highlights the advantages of VATS lobectomy over thoracotomy. The current results of the National Lung Screening Trial should also increase the number of

From the Division of Thoracic Surgery, ${ }^{a}$ Mount Sinai School of Medicine, New York, NY; the Department of Surgery, ${ }^{\mathrm{b}}$ Thoracic Service, Memorial Sloan-Kettering, New York, NY; and Thoracic Surgery, ${ }^{\mathrm{c}}$ Hackensack University Hospital, Hackensack, NJ.

Disclosures: Authors have nothing to disclose with regard to commercial support.

Read at the 91st Annual Meeting of The American Association for Thoracic Surgery, Philadelphia, Pennsylvania, May 7-11, 2011.

Received for publication May 10, 2011; revisions received Aug 11, 2011; accepted for publication Sept 22, 2011; available ahead of print Oct 19, 2011.

Address for reprints: Raja M. Flores, MD, Division of Thoracic Surgery Mount Sinai Medical Center 1190 Fifth Ave, Box 1028, New York, NY 10029 (E-mail: raja. flores@mountsinai.org).

0022-5223/\$36.00

Copyright (C) 2011 by The American Association for Thoracic Surgery doi:10.1016/j.jtcvs.2011.09.028 stage I lung cancers identified and further increase the number of VATS lobectomy procedures performed. ${ }^{2}$

Although a well-designed prospective randomized trial of sufficient power comparing VATS lobectomy with thoracotomy does not exist, good comparative studies have demonstrated equivalent oncologic outcomes, shorter lengths of stay, and fewer postoperative complications with the VATS approach. ${ }^{3,4}$ However, detailed accounts of intraoperative complications that would alert surgeons to these potential situations are lacking in the current literature. Increasing the awareness of such complications may be the best way to avoid them and facilitate performing VATS lobectomy safely. Therefore, we embarked on this study to quantify catastrophic intraoperative complications, describe potentially dangerous situations, and offer specific management strategies to limit morbidity should they occur.

\section{METHODS}

All patients who underwent VATS lobectomy or a combination of any VATS procedure plus a thoracotomy were identified from a prospectively maintained institutional thoracic surgical database after institutional review board approval. Patients selected for VATS lobectomy included those who had clinical stage IA suspected lung cancer seen on computed tomographic and positron emission tomographic scans. All 10 surgeons performed VATS lobectomies. A catastrophic complication was defined as an event that resulted in an additional unplanned major surgical procedure other than the planned lobectomy. The large denominator was used to 


\section{Abbreviations and Acronyms}

STS $=$ The Society of Thoracic Surgeons

VATS $=$ video-assisted thoracoscopic surgery

screen for the catastrophic complications. Our operative technique has been described previously. ${ }^{5}$

\section{RESULTS}

From 2002 to 2010, 633 VATS lobectomies were performed and 610 patients had any VATS procedure plus a thoracotomy (1 patient had a VATS followed by laparotomy). Patients who underwent a VATS procedure plus a thoracotomy contained the catastrophic complications. There were no deaths. Thirteen catastrophic complications were identified in $12(1 \%)$ patients. These included 3 main pulmonary arterial transections and 1 main pulmonary venous transection requiring reanastomosis, 3 unplanned pneumonectomies, 1 unplanned bilobectomy, 1 tracheoesophageal fistula, 1 membranous airway injury to the bronchus intermedius, 1 complete staple line disruption of the inferior pulmonary vein, 1 injury to the azygos/superior vena cava junction, and 1 splenectomy (Table 1). There were no predictors of catastrophic intraoperative complications nor was the level of the surgeon's experience a factor in their occurrence. There was an equal distribution of catastrophic complications among all surgeons. Complications occurred at all times: early, middle, and later parts of the learning curve. On final pathologic evaluation, the majority had stage $1 \mathrm{~A}$ disease, 2 had IB disease by size, and 2 had benign disease.

\section{Injuries of the Pulmonary Artery Bleeding}

Patient 1. Two cases of pulmonary artery injury led to pneumonectomy. The first was in an elderly woman with calcified lymph nodes. Transection of the superior pulmonary vein, bronchus, and truncus artery were performed successfully. The posterior ascending branch of the pulmonary artery had a number of adherent calcified lymph nodes that required dissection. Bleeding ensued and thoracotomy was performed. On inspection, a large portion of the wall of the pulmonary artery had been irreparably damaged, necessitating intrapericardial proximal arterial control and a pneumonectomy.

Patient 2. The second case was a delayed pneumonectomy performed on an obese woman who was undergoing a left upper lobectomy. Port placement was suboptimal, the utility incision was too low, and on dissection an injury to the first branch of the pulmonary artery resulted in a tear that required a thoracotomy to control and repair. Several days later the patient had a thrombosed pulmonary artery and opacification of the remainder of the left lung. The decision was made to perform a completion pneumonectomy. Pathologic examination of the upper lobe lesion returned as benign disease.

\section{Transection}

Patient 3. The patient was undergoing a VATS right upper lobectomy. The vein was transected. The entire main pulmonary artery was inadvertently transected and evident immediately. A thoracotomy was performed. The arterial staple lines were removed and a primary anastomosis was performed. The patient required a bilobectomy of the right upper and middle lobes owing to the location of the tumor. Patient 4. This patient was undergoing a VATS right upper lobectomy. On transection of the right upper lobe vein, it was apparent that the ongoing pulmonary artery had been unintentionally encircled and transected simultaneously with the vein. Thoracotomy was performed and the truncus artery had been spared in the process. The right upper lobectomy was completed and an anastomosis of the ongoing pulmonary artery to the main pulmonary artery was performed, sparing the right lower and middle lobes.

Patient 5. The patient had a proximal left upper lobe tumor with complications of 2 structures. After transection of the left upper lobe vein, the main pulmonary artery was mistaken for the first left upper lobe arterial branch. The left main stem bronchus was then transected. Once these were recognized, the patient underwent a thoracotomy. On inspection, it was deemed that the patient required a pneumonectomy from an oncologic perspective owing to the proximal nature of the tumor.

Injury to bronchi. As mentioned earlier with patient 5, the left main stem bronchus was transected after the main pulmonary artery was mistaken for the first left upper lobe arterial branch.

Patient 6. While undergoing a VATS right upper lobectomy, the patient had the right middle lobe bronchus transected while the anterior portion of the major fissure was being completed. Thoracotomy was performed. The patient underwent a right middle lobectomy as well, which resulted in an unplanned bilobectomy.

Patient 7. The patient underwent a VATS right upper lobectomy. During the right upper lobectomy, a membranous airway injury of the right main stem bronchus and bronchus intermedius had occurred, which required thoracotomy and primary repair.

\section{Injury of the pulmonary vein}

Patient 8. A patient with distal bifurcation of the inferior and superior pulmonary veins underwent a left upper lobectomy. Once the alleged left upper lobe vein was transected, it was apparent that both the left upper and lower lobe veins had been incorporated into the staple line. The lower vein was reanastomosed, the lower lobe preserved, and the left upper lobe was resected as initially intended. 
TABLE 1. Summary of catastrophic complications

\begin{tabular}{|c|c|c|c|c|c|c|}
\hline $\begin{array}{l}\text { Age }(y) \\
\text { sex }\end{array}$ & Lobe & Complication & Procedure & Pathology & $\operatorname{LOS}(d)$ & $\begin{array}{l}\text { Additional postop } \\
\text { complication }\end{array}$ \\
\hline $72, \mathrm{~F}$ & LUL & Transection of entire left PV trunk & Primary anastomosis & Stage $1 \mathrm{~A}$ & 7 & \\
\hline $54, \mathrm{M}$ & RLL & Bleeding PV retracting into pericardium & Primary repair & Stage $1 \mathrm{~A}$ & 4 & \\
\hline $80, \mathrm{~F}$ & RUL & Bleeding PA & Pneumonectomy stage & Stage $1 \mathrm{~A}$ & 8 & AFIB \\
\hline $50, \mathrm{~F}$ & LUL & Bleeding PA & Pneumonectomy (delayed) & Benign & 7 & \\
\hline $72, \mathrm{M}$ & RUL & Transection of PA distal to truncus & Primary anastomosis & Stage $1 \mathrm{~A}$ & 6 & \\
\hline $46, \mathrm{~F}$ & RUL (RML) & Transection of main PA & Primary anastomosis & Stage $1 B$ & 7 & \\
\hline $61, \mathrm{M}$ & LUL & $\begin{array}{l}\text { Transection of main stem bronchus and } \\
\text { left main PA }\end{array}$ & Pneumonectomy & Stage 1B & 5 & \\
\hline $60, \mathrm{~F}$ & RLL & Transection of RML bronchus & Bilobectomy & Stage $1 \mathrm{~A}$ & 6 & \\
\hline $58, \mathrm{M}$ & RUL & Membranous injury & Primary repair & Stage $1 \mathrm{~A}$ & 7 & Wound infection \\
\hline $57, \mathrm{M}$ & LUL wedge & Splenic bleeding & Splenectomy & Benign & 8 & \\
\hline $73, \mathrm{~F}$ & RUL & Bleeding azygos/SVC & Primary repair & Stage $1 \mathrm{~A}$ & 6 & \\
\hline $70, \mathrm{M}$ & RML & TE fistula & Muscle flap interposition/Eloesser & Stage $1 \mathrm{~A}$ & 14 & Rehabilitation \\
\hline
\end{tabular}

$L O S$, Length of stay; $L U L$, left upper lobe; $R L L$, right lower lobe; $R U L$, right upper lobe; $R M L$, right middle lobe; $P V$, pulmonary vein; $P A$, pulmonary artery; $S V C$, superior vena cava; $T E$, tracheoesophageal; $A F I B$, atrial fibrillation.

Patient 9. The patient underwent dissection of the right inferior pulmonary vein during a right lower lobectomy. On dissection of the bronchus, the lower lobe vein staple line opened and the vein retracted into the pericardium. Thoracotomy was performed, control was obtained, and the vein was oversewn. During the thoracotomy, it was apparent that the initial staple line had caught pericardium, which led to separation of the staple line.

\section{Injury of abdominal organs}

Patient 10. With this patient, the posterior port was placed in the usual location at approximately the eighth intercostal space. A VATS left upper lobe wedge resection for benign disease was performed. Postoperatively, the patient was hypotensive with a dropping hematocrit value. A computed tomographic scan demonstrated an injured spleen. The patient underwent a laparotomy and splenectomy. There was no diaphragmatic injury. The patient did well postoperatively.

\section{Mediastinal nodal dissection}

Patient 11. A successful VATS right upper lobectomy had been completed. A level 4 nodal dissection was in progress when a segment of the superior vena cava at the azygos/ caval junction was removed. Thoracotomy was performed and the injury primarily repaired.

Patient 12. The patient had multiple adenocarcinomas and underwent a right middle lobectomy, right upper and lower lobe wedge resection, and a level 7 mediastinal nodal dissection. Postoperatively, the patient had a slow but uncomplicated course and eventually was discharged home. The patient returned 2 weeks later with a left bronchoesophageal fistula. In the operating room, the patient underwent primary repair with muscle interposition. Six weeks after the initial procedure, the patient had a right-sided bronchoesophageal fistula to the junction of the right main stem bronchus and bronchus intermedius. Muscle interposition was again used. Two and a half months from the initial operation, he required an Eloesser flap for a persistent empyema. His condition has been satisfactory since then.

\section{CONCLUSION}

This study demonstrates catastrophic intraoperative complications during VATS lobectomy occur infrequently. Large single-institution case series have focused on the successful performance of numerous VATS lobectomies to document feasibility and safety rather than focus on the few cases that had gone awry. ${ }^{6,7}$ Comparative studies of VATS versus thoracotomy, even from our own institution, have failed to accurately capture this group of patients. ${ }^{3,4,8}$ Reasons for this shortcoming are likely multifactorial and include the following: retrospective nature of the studies, different definitions of VATS conversions to thoracotomy, methodology, ignoring the intent-to-treat principle, and database queries that have focused on lobectomies alone, which miss pneumonectomy cases resulting from complications. The possibility that no major intraoperative complications occurred in these large studies seems unlikely. Therefore, a concerted effort by VATS surgeons to identify these cases is essential so that others can learn from them.

One of the few prospective studies on VATS lobectomy reported by the Cancer and Leukemia Group B included 111 attempted VATS lobectomies from 11 experienced surgeons. The study did not comment on any major intraoperative complications. However, given the small number of cases per surgeon, it is quite possible that none occurred. Of note, the conversion rate was $14 \%$, which may reflect a level of added caution by experienced VATS surgeons. ${ }^{9}$ A retrospective VATS versus thoracotomy study using the STS database could not adequately address the question of conversion rate owing to inherent database limitations, which greatly undermines conclusions in any VATS study. ${ }^{8}$ 
A universal definition of conversion rate is lacking and intraoperative complications of VATS lobectomy are usually hidden within these converted cases.

Recently, a study using the Healthcare Cost and Utilization Project Nationwide Inpatient Sample database, an insurance database, concluded that VATS lobectomy was associated with a greater number of intraoperative complications than open lobectomy. ${ }^{10}$ As with conversion rates, the definition of intraoperative complications can be ambiguous as well. Their definition included accidental puncture or laceration, foreign body accidentally left during procedure, and bleeding complicating procedure. However, many believe this database may not capture the desired end points accurately inasmuch as its primary purpose is to address health care costs. In addition, the level of thoracic expertise as reflected by the rate of VATS lobectomy was lower $(6 \%)$ than what is available in the STS database $(20 \%)$.

Several articles have focused on troubleshooting and have outlined a predetermined stepwise plan to introduce VATS lobectomy into their thoracic training programs. ${ }^{11-13}$ Although these articles try to facilitate the performance of a successful VATS lobectomy, they do not provide specific situations to be aware of and none describes measures to address these situations should they occur.

The incidence of catastrophic intraoperative complications during VATS lobectomy is low but, when they do occur, they are manageable. Avoidance is enhanced by solid knowledge of the anatomic relationships, careful dissection, awareness of the potential complications described in this report, and judicious conversion to thoracotomy when appropriate. However, should a catastrophic complication occur, surgical approach should focus on lung-sparing techniques as described to limit morbidity. By following the guidelines presented in this study, surgeons will take proper caution in performing VATS lobectomies.

\section{References}

1. Boffa DJ, Allen MS, Grab JD, Gaissert HA, Harpole DH, Wright CD. Data from The Society of Thoracic Surgeons General Thoracic Surgery database: the surgical management of primary lung tumors. J Thorac Cardiovasc Surg. 2008;135: 247-54.

2. Aberle DR, Berg CD, Black WC, Church TR, Fagerstrom RM, Galen B, et al. The National Lung Screening Trial: overview and study design. Radiology. 2011;258:243-53.

3. Flores RM, Park BJ, Dycoco J, Aronova A, Hirth Y, Rizk NP, et al. Lobectomy by video-assisted thoracic surgery (VATS) versus thoracotomy for lung cancer. J Thorac Cardiovasc Surg. 2009;138:11-8.

4. Flores RM, Ihekweazu U, Rizk N, Dycoco J, Bains MS, Downey RJ, et al. Patterns of recurrence and incidence of second primary tumors after lobectomy by means of video-assisted thoracoscopic surgery (VATS) versus thoractomy for lung cancer. J Thorac Cardiovasc Surg. 2011;141:59-64.

5. Flores RM. Video-assisted thoracic surgery (VATS) lobectomy: focus on technique. World J Surg. 2010;34:616-20.

6. McKenna RJ, Houck W, Fuller CB. Video-assisted thoracic surgery lobectomy: experience with 1,100 cases. Ann Thorac Surg. 2006;81:421-6.

7. Onaitis MW, Petersen RP, Balderson SS, Toloza E, Burfeind WR, Harpole DH Jr, et al. Thoracoscopic lobectomy is a safe and versatile procedure: experience with 500 consecutive patients. Ann Surg. 2006;244:420-5.
8. Paul S, Altorki NK, Sheng S, Lee PC, Harpole DH, Onaitis MW, et al. Thoracoscopic lobectomy is associated with lower morbidity than open lobectomy: a propensity- matched analysis from the STS database. J Thorac Cardiovasc Surg. 2010;139:366-78.

9. Swanson SJ, Herndon JE II, D'Amico TA, Demmy TL, McKenna RJ Jr, Green MR, et al. Video-assisted thoracic surgery lobectomy: report of CALGB 39802 - a prospective, multi-institution feasibility study. J Clin Oncol. 2007; 25:4993-7.

10. Gopaldas RR, Bakaeen FG, Dao TK, Walsh GL, Swisher SG, Chu D. Video-assisted thoracoscopic versus open thoracotomy lobectomy in a cohort of 13,619 patients. Ann Thorac Surg. 2010;89:1563-70.

11. Reed MF, Lucia MW, Starnes SL, Merrill WH, Howington JA. Thoracoscopic lobectomy: introduction of a new technique into a thoracic surgery training program. J Thorac Cardiovasc Surg. 2008;136:376-82.

12. Ferguson J, Walker W. Developing a VATS lobectomy programme-can VATS lobectomy be taught? Eur J Cardiothorac Surg. 2006;29:806-9.

13. Demmy T, James T, Swanson S, McKenna R, D'Amico T. Troubleshooting video- assisted thoracic surgery lobectomy. Ann Thorac Surg. 2005;79:1744-53.

\section{Discussion}

Dr Daniel L. Miller (Atlanta, $\mathrm{Ga}$ ). I congratulate you on your honesty in bringing this to the forefront.

It is interesting that there were 12 patients who were injured in this study. That is the same number of patients who had major complications in Dr Park's robotic series. Were any of these robotic?

Dr Flores. No.

Dr. Miller. Good answer.

The thing that concerns me is that a lot of this involves anatomic issues, especially in regard to the pulmonary artery and pulmonary veins. Total transection of the pulmonary artery and the bronchus is like a Ralph Lewis procedure. The big thing is, what have you learned from this and what can you tell the audience? When you do bronchial stapling, you can do a ventilation test, even though you had one issue with the middle lobe vein, but what can you do to prevent this from occurring again to the pulmonary artery and especially the pulmonary veins? As you know, $15 \%$ to $20 \%$ of the time there is a common vein on the left side. What can you tell us on how to prevent this?

Dr Flores. I have learned many things from reviewing this series. The first is that it is very difficult to identify these patients from large databases. Frequently, the query is looking for lobectomies, and that will miss the pneumonectomies that are performed as a result. I think these complications are actually underreported in the literature.

With every structure, I have learned a huge deal when it comes to VATS lobectomy. With the vein, if there is any doubt, take down the inferior pulmonary ligament. Identify that inferior pulmonary vein. Identify the superior pulmonary vein. It takes a little more time, but that is what you need to do. When it comes to the pulmonary artery, I use two rules of thumb. First, make sure the artery is continuing. When you see a branch, don't just take it. Make sure you see more artery going down to the rest of the lung. Avoid the crotch. A lot of the bleeding comes from going into that crotch, so go a little bit higher. That will protect you from major bleeding.

As you said, most of us do the bronchus openly, inflating the lungs before transection. I think another key is, if there is any doubt about a middle lobe bronchus being hidden in the fissure, maybe during that situation you want to inflate as well and identify that you could possibly have included that in the fissure. 
When it comes to the intra-abdominal injuries, I think that in this particular case, the VATS was performed in the usual way that most of us would perform it. There was no diaphragmatic injury. What happened was that the fellow continued to push the stapler into the chest, met some resistance at the skin, kept hitting the diaphragm and hitting the spleen underneath, and that is what led to an injury. So when you have someone inexperienced on the other side, make sure that you watch him or her directly and that that stapler is going up and not hitting the diaphragm.

Dr Sugarbaker. Raja, try to be brief. We have a lot of people who want to discuss your paper.

Dr Miller. The second question is in regard to the lymph node dissection. Two of the injuries, one to the bronchus and one to the vena cava, were probably related to the technique of removing that, because sometimes you can ring forcep, pick up, and cauterize. We have switched to an energy device. We use the EnSeal device (Ethicon Endo-Surgery, Inc, Cincinnati, Ohio), but a LigaSure vessel sealing system (ValleyLab, Boulder, Colo), or any bipolar, can also be used That cuts down on that inadvertent injury to those associated vessels. Can you comment on that?

Dr Flores. Any kind of new technology warrants practical use. I know you and Dr Swanson both are enthusiastic about the energy devices. I do not use them. I use cautery and the argon beam, as does everyone else on our team. However, I think it is important to go ahead and look into that. There was an injury with the left upper lobectomy that I think was as a result of the argon beam, and then on blunt dissection, the artery opened up. I think we have to be very careful about vascular injuries, and maybe the energy will come into play with that.

Dr Miller. The last thing is in regard to quality assurance. It is very important after these events occur that you have a debriefing with your team in the operating room. The nurses suffer. They feel terrible. It is very important to get the team involved in discussing how to prevent complications in the future. If you do not do that, there will be future ramifications.

Dr Flores. That is a huge point. We are going to start doing that at our institution.

Dr G. Alec Patterson (St Louis, Mo). Raja, you should be congratulated. You have a lot of courage and a lot of honesty.

This just reinforces my conviction. This is for everybody in the room. If you want to get an abstract accepted at the AATS, all you have to do is put the word "complication" in the title. I was also going to say that it's a good thing there were only 12 cases, because you never would have gotten through it otherwise. [Laughter.]

Just for clarification, it seems to me that another big problem is injuries that occur to various structures that result in a thoracotomy but do not change the ultimate operation. For example, a hole in the pulmonary artery or in the vein means that you have to make a big operation out of it, but the patient still just gets a lobectomy. Were those patients included in this report?

Dr Flores. No.

Dr Patterson. Even patients who had a major amount of blood loss?

Dr Flores. We tried to focus in on patients who required some other separate procedure. Now, I included a couple things, like the superior vena cava injury, just because I thought they were good learning points. However, in the patient who had a pulmonary artery injury where we just took a few Prolene polypropylene sutures (Ethicon, Inc, Somerville, NJ) to oversew it, even if the patient required a unit of blood, we did not include that. That is actually included in our initial paper from 2009 in which looked at the complications, and there were 11 of those.

Dr Thomas K. Waddell (Toronto, Ontario, Canada). I am interested just to get into the exploration of why the injuries happened. I think you did a pretty good job of that, but if I understood it correctly, it was just from reading the operative notes. You did not have the opportunity to review videos or to interview the surgeons involved.

Dr Flores. No, I actually did interview the surgeons. We identified the patients from looking at the operative notes. Once we had the operative notes, I contacted each individual surgeon and discussed the case to get specifics.

Dr Waddell. I think it would be very interesting in this kind of analysis to try to break it down in terms of cognitive versus technical misadventure. I really applaud you for doing it. It's very, very helpful.

Dr Flores. Thank you.

Dr Scott J. Swanson (Boston, Mass). I think you should be a little more circumspect, because many injuries that occur during thoracotomies are due to lack of understanding of anatomy and misidentifying anatomy. At least half of your complications were related to misidentifying anatomy, and so I find it hard to believe it is not related to experience. When I first began doing VATS, there were a lot of issues around identifying what we were doing. I think experience plays a huge role. You are already saying you know tips to look for veins and look at the arteries. That's experience. So I would say (1) this is not just VATS, it's surgery; (2) I do believe it is related to experience.

Dr Flores. One of the main points of this paper is that no matter how experienced you are, it can still happen. You have to be very vigilant. I do agree with you. I think that with experience, you get a much decreased rate of your conversions, but even if you're the most experienced VATS surgeon, this can still happen.

Dr Tomasz Grodzki (Sczcecin, Poland). Raja, it was a fantastic paper. I have 2 two short questions.

First, were those complications connected somehow with a learning curve or did they happen during maturity? Second, I appreciate both teams and the legendary Sloan-Kettering team. The question is a little bit discreet. Was the distribution of those complications rather equal, or were there some leaders?

Dr Flores. The complications were not by any one specific surgeon. Each surgeon had at least one or two. And I think it is important that we learn from these experiences so that it does not happen when we do it. I've learned from just writing this paper.

Dr Hiran C. Fernando (Boston, Mass). As well as the learning curve, were there tumor factors that may have helped you predict these complications happening in advance, or patient factors, such as adhesions? Have you been able to devise any drills or backup plans within your team, so that if you have cases like this, you know how you are going to handle it?

Dr Flores. We looked at that. We tried to figure out if we could predict anything that could lead us to identify these complications. Most of the worst complications were on little, tiny things. As you saw, there was even a pneumonectomy for benign disease. So it is 
very difficult to predict. It does not correlate with the learning curve, it does not correlate with the surgeon's experience, and I think this just stresses the fact that we have to maintain a level of vigilance when doing these operations. We cannot let our guard down, ever.

Dr Dominique Grunenwald (Paris, France). Thank you, Raja. I appreciate your modesty, as usual.

I have a question about patient 4, who had thrombosis of the pulmonary artery after the operation. Did you give anticoagulation therapy to this patient during the arterial clamping?

Dr Flores. When it comes to a primary anastomosis, we do not anticoagulate. In this particular patient, it is interesting that a pneumonectomy had to be performed, because the main pulmonary artery can be tied off and patients can do well with that, as recently reported in the Journal of Thoracic Surgery in a series of letters to the editor. So actually we do not use anticoagulation, and we did not do so in that particular patient.

Dr Grunenwald. This goes along with the question to Dr Galetta yesterday, who did not give anticoagulation therapy during arterial clamping. Personally, I think it is necessary to give such anticoagulation therapy.

Dr Stephen C. Yang (Baltimore, Md). Again, thanks for confessing your sins.

You said you did not have a complete database for the ability to check all complications. One of the things I always worry about is taking out the wrong lobe. You have got a spot and you are not exactly sure. It is sitting in the fissure. You look at the 3-dimensional reconstruction, and you are still not quite sure. That happened to me once. I was just curious how often that might happen.

Dr Flores. I appreciate your candor with that. That is something that frightens me to death, and I have opened patients because I could not really identify the lobe. The first thing that I explain to the residents before starting the dissection is that my best instrument is my finger. I put it in there, I make sure I feel where that tumor is, and I will not start the dissection until that happens. If there's a doubt, I will open.

Dr Yang. You went through a lot of them in detail. I didn't quite understand how you get bilateral fistula from a right middle lobe, the esophageal fistula.

Dr Flores. That is an interesting case. That patient underwent a level 7 mediastinal nodal dissection, and I do not know how that happened. The patient was probably the one who was doing the worst out of all the complications, and I do not know how to learn from that. Maybe we need to look at the American College of Surgeons Oncology Group study of dissection versus sampling. However, you should not change your operation from thoracotomy when you are doing it VATS. If you believe in nodal dissection, complete nodal dissection, then you should do the same with VATS.

Dr Todd L. Demmy (Buffalo, NY). Have you thought of using a video bronchoscope that the anesthesiologist can pass to help identify whether or not an airway is being pinched or narrowed? That's useful for the airway complications. For the ones in which you were unaware of the vessel you were taking in the superior hilum, were you using a high-definition scope or were you able to get your scope at enough of a right angle so you were really looking at the lateral hilum so you could see those vessels emerging? Could that have been an issue for those transection issues?

Dr Flores. I think it depends on which surgeon you ask. All of us were using $30^{\circ}$ scopes. Initially we were using regular scopes, then we transitioned to high-definition scopes, and it did not appear that that came into play. I think your idea of using a bronchoscope is helpful in cases in which there is a question. But the thing to note in this study is that a lot of VATS lobectomies were performed successfully. A total of 633 VATS lobectomies performed successfully is not a small number. That is the reason you have to always keep your eyes open for one of these potential complications, because I think a problem will hit you when you least expect it. 